\title{
18. The Australian Government Cabinet Implementation Unit
}

\section{Peter Hamburger, Department of the Prime Minister and Cabinet}

My purpose is to address a particular managerial initiative in the Australian Public Service - the Cabinet implementation Unit - an initiative that is now about two-and-a-half years old and that reports to me.

One might, therefore, expect me to talk about the management role of the Unit but, in fact, I am going to start with the politics.

I will do that because, contrary to the expectations and hopes of many public servants, the Cabinet is primarily a political, not a managerial, institution and a body called the Cabinet Implementation Unit will therefore be located at the boundaries of politics and management. The political dimension will always affect what the Unit can do and how it can do it.

I gave a talk on Cabinet processes to senior officials of the Department of Finance some months ago and emphasised - to the point of tedium, I thought - that Cabinet is a group of politicians, performing the hugely valuable role of politics in a democratic society and that as a result they might not always appear rational to public servants. Their first question was 'why do they so often ignore our good advice?'

I had clearly failed to convey the message that politicians, when they collectively consider the political aspects of government decisions, are likely to take into account factors beyond costs and benefits, probabilities, and the nitty gritty of how to implement the decision. They are quite properly interested in the politics as well.

In our system Cabinet is about decision-making, coordinating government activity building and maintaining cohesiveness all at the political level. Cabinet decisions will naturally be based on the political judgments of the leading members of the political party that has been given a parliamentary majority by the people of Australia - and this is perfectly proper.

They will also be made under a constitution in which the responsibility for managing rests with the Queen's Ministers of State and the Departments of State they administer not the collective Cabinet which, like the Prime Minister, is not mentioned in the constitution. In practice, as well as in law, the responsibility for making a change in policy happen after the collective Cabinet has decided on it rests with individual ministers and their portfolio agencies. 
So the two big impacts of the political dimension are:

- Government will always have an eye on the politics; and

- the politics within the Government involve tensions between individual responsibility of ministers and collective responsibility of Cabinet.

The size and complexity of modern government has greatly increased the amount of managerial work that has to be done at the ministerial level. I like to draw the contrast with the Australian Public Service of 1901: seven departments, eleven-and-a-half thousand public servants, 89 per cent of them in the Post Office.

The figures show that on size grounds alone Cabinet needs to be interested in implementation, however, size is not the only issue. Delivery is now a lot more complex:

- in many cases it has been moved outside government altogether, with government becoming a purchaser rather than a direct provider of services;

- very often, and increasingly, there are partnership, joint provision, or complementary provision arrangements, often across jurisdictional boundaries;

- even where government is the sole provider, that is often contestable or open to challenge;

- technology has very greatly widened the capacity for policy makers and implementers to interact, both in terms of the data processing that can happen and the extent to which higher level policy makers can by pass hierarchies (I have elsewhere used the 'strategic corporal' analogy); and

- customers for all sorts of services, including those provided by government, have become more demanding as they experience what can be provided in other areas.

Expectations have moved from the Model T Ford, with no options, even for colour, to the latest Fairlane which, if you buy it new, you can almost have built to your own specifications. Government service delivery has moved from the old clerical factories to complex networks like Centrelink and Job Network.

Cabinet and ministers are all held accountable in this very complex managerial environment and implementation failures often do lead to large difficulties for governments, for example:

- the Customs cargo management system threatened to leave everyone's Christmas presents on the wharves last year and bankrupt retailers;

- the Pay TV licensing in the later years of the previous Labor government caused enormous problems for that Government;

These are just two examples where ministers found that ignorance was no excuse, or at least did not ease the political pain very much. 
It is self-evident from all this that we need much stronger support structures for Cabinet decision-making and much stronger linkages between the political and the managerial levels of government now than our forebears did in 1901, or even in 1970.

That is where the CIU fits in. It gives Cabinet a capacity to oversee implementation and an opportunity to be involved in, or at least in control of, the learning and adaptation that occurs in the implementation process.

In principle also, Cabinet is well suited to this:

- coordination is one of the central functions of Cabinet and many of the most difficult implementation problems arise at boundaries between agencies, portfolios or jurisdictions where Cabinet coordination occurs anyway;

- implementation is in part a learning process in which the policy and delivery elements interact to produce improvements in policy as well as delivery, and cabinet is high-level forum for collective policy making in government; and

- if an issue is important enough for Cabinet to have decided it, the issue should be important enough for Cabinet to keep track of how it is going.

But, whatever the in-principle arguments might be, in practice it is very much up to the Prime Minister of the day, having regard to the dynamics of the Cabinet they chair and the party they lead to decide whether and how something that is desirable in principle should actually happen: it is certainly up to the Prime Minister to lead on whether the practical system that is located with Cabinet and not somewhere else in the governmental structure.

The fact that this topic is on your program today and that it is me talking to it is proof that the present Prime Minister has decided that:

- the Government should pay more systematic attention to implementation; and

- that it should be done through Cabinet.

The Prime Minister has clearly set out his preferences and there is no doubt that the recent interest in implementation planning and monitoring very much follows a prime ministerial lead. Consequently, the arrangements that I will be talking about are, in the end, contingent not only on how well they work but also on personalities in the top political positions and the way particular personalities choose to operate.

That said, it is often useful to see Cabinet as a broader entity than the seventeen ministers who meet every week or two and an entity that consequently has elements that last beyond the tenure of particular prime ministers. The broader concept of Cabinet is that it includes the set of processes and procedures and the direct bureaucratic support that centres on the meetings of ministers: 
- the history in Australia has been that the elements of the broader Cabinet system beyond ministerial membership tend to be sticky;

- procedural innovations that work have tended to survive and the greater part of our current Cabinet system is an accretion of past procedural innovations that have long survived their political parents.

There is good reason to think that if we build within the broad concept of Cabinet a workable and useful set of processes that focus on implementation, they will survive the inevitable future changes of personnel in the Cabinet narrowly conceived. That is our driving ambition anyway. We hope that the system we have set up has a degree of sustainability beyond the term of the present Prime Minister. One of the arguments for having a permanent public service is the capacity for thinking about the longer term.

So what are we actually doing?

One of our key initiatives has been to set up a Cabinet Implementation Unit, which has had a staffing level in the range of six to 12 for the past two-and-a-half years.

Our work so far has been of three broad types:

- ensuring that better information is put before decision-makers at the decision-making stage - a modest extension of the traditional cabinet support role;

- organising selective and targeted follow-up of decisions;

- and, partly as a spin-off from the other two, helping to change the way people think about implementation relative to policy and how they plan for implementation.

How are we doing it?

First, we have tweaked the cabinet drafters guide to require that proposals coming forward that have any significant implementation implications cover off on standard implementation issues:

- policy objectives;

- deliverables;

- milestones;

- the range of stakeholders (an important indicator of implementation complexity);

- risks; and

- governance arrangements.

The CIU, as matter of routine, checks draft proposals on their way to Cabinet and improves the quality of the information and argument going forward on 
implementation. Generally we end up with reasonable summary information on the important things that bear on implementation.

I should note at this point that Ministers do not have to read the implementation summary for the system to work, although it is clear that many do read them in important cases. But, most importantly, they can draw some comfort that these issues are being addressed and that, crucially:

- that the proponents of proposals, including ministerial proponents, have had to think through the issues and the defensive arguments as they prepare the document; and

- that the staff and public service briefers of ministers having studied the implementation attachments;

We are satisfied that the discipline is producing better outcomes.

If a key proposal is accepted, the implementation assessment must be expanded into a full implementation plan, lodged with the CIU. We work collaboratively with agencies in finalising the plan to ensure that it treats the relevant issues appropriately. We then use the plan to support structured follow-up of decisions. This gives us a basis for:

- assessing whether the project and its risks are such as to warrant keeping the Government informed of progress; and

- an agreed statement of the key milestones at which information will be potentially useful.

Essentially we pick up the higher-risk/higher-interest initiatives and provide a summary report every three months to the Prime Minister and then to Cabinet:

- the core of the report is a table presenting Green, Amber or Red traffic lights against the selected initiatives and measures within them;

- on top of that is a short summary of the Ambers and Reds and any notable points from the Greens;

- the number of initiatives being covered has risen as decisions are made that come into our net (there are currently about 70 initiatives comprising about 180 individual measures) but we expect to plateau about 10 to 15 per cent above this;

- to put some scale on this, the Cabinet makes something over 300 substantive policy decisions in a typical year;

- not all of them pose significant implementation issues and implementation does not last a full year in all cases (although sometimes it takes longer); and

- the 70 that do is a significant number but one that is both a manageable preparation task for us and a comprehensible product for ministers. 
The early experience has been that this is a very effective communications system:

- from the point of view of our Cabinet-level leaders:

- it presents information in a manageable format; and

- it quite rigorously filters a lot of information so that the bits that interest them are at the top and helpfully colour coded.

- from the public service point of view:

- it is not frightening since it provides an early and hence usually fairly low-key opportunity to point to problems;

- confessing at that stage means one's misery has company since there are always a number of Amber and Red lights across a good spread of portfolios;

- there is a strong incentive not to hide looming failure since it is not generally career enhancing to assure the top of government that things are going well shortly before the train falls off the bridge; and

- you are able to look good if things are travelling well.

Beyond the follow-up activity on initiatives being monitored, the Unit also has authority to conduct larger scale reviews in areas where we think there might be implementation issues worth pursuing. The Prime Minister's Delivery Unit in the UK has this function and has pursued it vigorously and, as far as I can see, with some success.

As far the CIU's review role is concerned, I think it is fair to say that so far it has been pretty much a flop:

- there are obvious sensitivities about the Prime Minister sending his Department officers in to review work in other portfolios;

- the Unit is not sufficiently staffed to do serious reviews and the Unit itself does not have the clout to do the sort of work the UK Delivery Unit does;

- we have not yet developed an approach to or methodologies for review activity that show any promise.

While I have not yet given up on finding a proactive role for the Unit in review work, I have yet to find a way to do it.

What I know, however, is that if we are to successfully undertake this function, we will need to be very selective, to focus on successes as well as failures, and work with the relevant line departments and agencies to get the best possible advice to the top of government.

The Unit has, however, been active in looking at systemic issues and played a significant role in the development work that led to the Australian Government adopting the system of Gateway Reviews discussed elsewhere in the program. 
Also discussed elsewhere in the program is a better practice guide to implementation of program and policy initiatives. We have been working with the Australian national Audit Office on this and expect it to be released in a few months.

I mentioned that changing the way people think about implementation is also an explicit part of the Unit is charter. We get out a fair bit in a variety of forums to spread the message about the need to keep implementation issues in mind at all stages of the policy cycle.

Some of that effect comes anyway from the work people have to do to meet the new planning and monitoring requirements:

- there is a useful discipline of having to deal explicitly with implementation in the initial proposal to Cabinet:

- then and in the later monitoring phase, the system forces the policy proposers to talk to the intended implementers, if they are not the same people as they often are not (i.e. it is good to see the left hand working with the right);

- we have had some suggestions that our processes have helped people drafting proposals to think beyond the details of delivery and place their proposals into the context of broader government policy;

- we think that the process changes have also nudged the policy people in $\mathrm{PM} \& \mathrm{C}$ to pay a bit more attention also to implementation issues.

In a few cases departments have set up project management or similar units to improve and monitor their own implementation activities and we do quite a lot of work with those counterpart units to improve the implementation of new and existing measures.

I started by noting that Cabinet's interest in implementation has been pretty much led from the top and the durability of anything flowing from it is consequently vulnerable in the medium to long term.

It is pretty much axiomatic that getting government policy properly implemented is going to be important to whomever is in government and that the sorts of things we are doing should be done:

- however, no-one can rely on things happening in government just because they make sense;

- and we cannot expect them to result simply from declaration of their importance; and

- the test will be whether the structures we have set up deliver something of value and survive well into the future.

So what are some of the key things we have found so far? 
- most of the initiatives that are selected for this sort of high-level visibility start off as Green lights and stay that way;

- most of the others do not get beyond a watching brief;

- we are able to tell ministers that something will be a bit late or fall a bit short of target in some other way but ensure that expectations are managed and no real damage occurs ;

- a small proportion clearly need follow-up and our monitoring system is being successful in starting action on these a bit earlier and a bit more vigorously than would otherwise be the case;

- we have produced some empirical evidence for various points that probably could have been taken as bleeding obvious:

- within an agency, top level commitment to, and attention to, delivery is crucial;

- many projects that depend on alliances within or beyond the APS get into difficulty because there has been insufficient attention paid to whether such alliances will work;

- cross-jurisdictional or cross-sectoral, urgent, and politically sensitive initiatives are usually harder to do than initiatives completely within the control of a single minister and agency;

- some things get in the way of other things, for example when you add up the huge amount of ICT procurement that underpins every Budget, it is hardly surprising that a lot of these projects have to re-phase their expenditure, because they just cannot get their procurement process for the contractors or specialists to line up with their Gantt charts. This is an area the Unit now pays considerable attention to, in reviewing new policy proposals;

- the greater the uncertainty, the harder it is to do things; and

- shit happens.

But even if these seem to be platitudes, a system that keeps a whole-of-government perspective on the progress in implementing key decisions offers a lot of advantages in terms of both an early adjustment of expectations and early corrective action.

For this reason, I have high hopes that the changes the Unit has introduced will stick, largely because the changes we have made are not only simple and robust but they are also small, bureaucratic, low-cost, non-threatening and add value to both government and taxpayers alike.

That may not sound glamorous - members of the Unit sometimes chide me for not taking a higher tone in describing their work:

- but minor bureaucratic changes that have slipped into the cabinet process over the years tend to be the changes that have stuck once they got there; 
- also, of course, our changes self-evidently do good things and we should not be so cynical as to assume that that will be discounted; and

- usually, in fact, political decision-makers set out to do good rather than harm.

The changes are quite well-pitched strategically: although small and bureaucratic, they are located at points in the cabinet process where they cannot very easily be avoided and they set up incentives that are wholly positive.

Perhaps most importantly, after a relatively short time in operation we are beginning to see the Unit add some value to the policy process.

In particular, it is no longer enough for those advocating major policy to have a good idea. We know that there are many good ideas that originate in Canberra! We are now constantly reminded that the Government demands that that we think through our ideas and how they are going to be implemented. Overall, we are pretty optimistic that we are doing good things and that what we are doing is being well received. But you can bet your bottom dollar that we will not be resting on our laurels. 